free from the disease; and inspectors should be appointed to make daily visits to their respective districts, and report all cases of diarrhœea, etc. Supplies of medicine for the treatment of diarrhœea should be lodged with them, and made readily available to all applicants; and extra allowances in the shape of beef-tea, etc., should be given to those of the poorer classes who might be attacked with diarrhoea.

One important feature deserving of attention was that, during the prevalence of cholera, the cases requiring medical attendance for other forms of disease were very exceptional; it seemed as if this dire epidemic had swallowed up all the minor ills.

\section{ON ANÆSTHETICS.*}

BY THOMAS J ONES, M.D.,

Assistant-Physician to Victoria Hospital for Sick Children; formerly (for eleven years) Resident Medical Officer and Administrator of Anæsthetics to

$$
\text { St. George's Hospital. }
$$

2. Ether was first employed by me as an anæsthetic at St. George's Ilospital in the year 1861. Although it was administered on a large conical sponge (a very objectionable mode), I succeeded in almost all cases in producing the necessary degree of narcotism. It was given for several capital operations, and in cases requiring careful dissection, such as hernix, with complete success. In the following year I discontinued its use, however, in the operating theatre, on account of the inconvenience occasioned to those present by the smell of the vapour, and from the time it took in some cases to get the patient under its influence, which was a very serious objection when several had to be operated upon. I, however, continued its use in cases which were considered unsafe for chloroform, such as those in a state of collapse from severe accidents. The stimulating effects of ether in such cases were attended with remarkably good results : they were generally in a better state after than before the operation.

In a paper read on this subject before St. George's Hospital Medical Society in 1863 , I observed that the result of my experience to that time tended to show (I) that ether caused during the first stage more cerebral excitement than chloroform ; (2) that it produced a greater degree of anæsthesia before the consciousness was completely abolished; (3) that during the stage of very complete unconsciousness, the reflex function of the cerebro-spinal centres was not abolished to the same degree as under chloroform ; (4) that it stimulates instead of depressing the heart.

My subsequent experience confirms, in the main, these conclusions. Ether, unlike chloroform, would seem to exert no paralysing influence on the heart, carried to the extent necessary for the performance of operations. In the paper referred to, I related two cases in which ether was administered with good effect after chloroform had been tried and found to produce dangerous symptoms.

Dr. Snow states (On Ancesthetics, p. 362) that "ether is altogether incapable of causing sudden death by paralysis of the heart, which has caused the accidents which have happened during the administration of chloroform. I have not been able to kill an animal in that manner with ether even when I have made it boil, and administered the vapour almost pure. The heart has continued to beat after the natural breathing has ceased, even when the vapour has been exhibited without air. .

I hold it, therefore, to be almost impossible that a death from this agent can occur in the hands of a medical man who is applying it with ordinary intelligence and attention". When this passage is taken in connection with the fact that Dr. Snow records in the same work no fewer than fifty fatal cases from chloroform, it is very wonderful that he should still persevere in the use of chloroform, especially when we find he observes (op. cit.) that he "usually rendered adult patients insensible in four or five minutes, and children in two or three", and that he "never failed to make the patient insensible in any one instance in which ether was administered". Hence, ether being in his hands perfectly successful and manageable, I cannot help agreeing with the opinion advanced in the leading article in this JouRNAL of the 16 th instant, that he, like every one else, was considerably influenced in the choice of the anæsthetic which he used by the energetic and uncompromising advocacy of the discoverer of chloroform.

I think the disadvantages of ether over chloroform are really very few and trivial. I find that some prefer the flavour of ether-vapour to that of chloroform. Its pungency, when inhaled, only lasts a few seconds, and not at all in some cases, when properly administered. As to the question of cost, I also think this objection has been exaggerated. Methylated washed ether (which answers all purposes quite as well) can be bought for half-a-crown a pound. If the anæsthetic be given

* Continued from page 577 of last number. rapidly and unsparingly at the commencement, I do not think the dose for each patient should cost more than sixpence-so that, in fact, the cost is not much greater than that of chloroform.

With reference to the mode of administration, I think the plan recommenaed by our American friends is as good as any-namely, a thick towel, in half-dozen folds, arranged in the form of a cone. Care should be taken that its base should be large enough to take in the chin and the nose-its shape such as to fit the face accurately. A small sponge should be placed inside, which should be squeezed out of warm water after each case, to prevent its becoming so cold as to interfere with the evaporation of the ether. Mr. Warrington Haward's apparatus, described in this JOURNAL on the 2 nd inst., is also a convenient method of administering it, and answers very well. But I find that the oiled silk, which forms its external layer, is an objection, because it interferes with the conduction of heat from the hand into the interior of the cone. In a cone covered with the oiled silk, the interior becomes so reduced in temperature that the evaporation of the ether is considerably checked.

Thinking that an inhaler would effect, amongst other advantages, considerable saving of the ether, I have had for some time my attention directed to this point, but have not as yet succeeded in suggesting any improvenient upon the one adopted by Dr. Snow.

3. The Combination of Chloroform and Ether.-My experience, in the main, confirms the opinion held by Dr. Snow, that the combination of these two liquids combines the undesirable qualities of both. When the two agents are combined in their liquid state, one never knows what one is about. I should not have considered it necessary to allude to this point, had I not seen a communication from Dr. Edis in the JOURNAL of November I6th, still advocating this method-one which, I thought, had been given up some time since. I have, however, been in the habit for some years past of administering the vapours of these two agents to the same patient with considerable advantage. I begin with chloroform ; but as soon as the pulse shows signs of failure, I commence the administration of ether, and continue its use until the pulse is restored, or as long as the patient remains quiet enough for the performance of the operation. In this manner, I believe, the cases of avoidable deaths from cardiac failure resulting from chloroform might be averted.

4. Nitrous Oxidi:- When I consider the safety, ready applicability, and the pleasantness of this agent, together with the success attending it, I confess I am surprised that surgeons do not adopt it more generally than they do for the minor operations requiring but few minutes in their performance. I have succeeded in keeping the patients under its influence for eight or ten minutes by its reapplication from time to time. I think that for some cases of operations about the eye its use would be invaluable, seeing that it produces no sickness.

\section{NOTE ON THE ADMINISTRATION OF ETHER.} By JOHN COUPER, F.R.C.S.,

Surgeon to and co-Lecturer on Surgery at the Lond nn Hospital ; Senior AssistantSurgeon to the Royal London Ophthalmic Hospital, Moorfields.

SOME years since, ether was repeatedly administered at the London Hospital, with unsatisfactory results. Although it was given in a full dose, complete narcotism was not speedily obtained, and was preceded by excitement and violent agitation of the limbs. The ether then used had not been specially prepared, and in all probability was not anhydrous. Certainly, its effects on these occasions were entirely different from those with which I have since become familiar, when pure anhydrous ether has been employed.

Having repeatedly seen the administration of ether by Dr. Joy Jeffries last August, I have since employed it exclusively, and propose now to state, briefly, the results of this short trial. The chief operations performed have been ovariotomy, lumbar colotomy, amputation through the knee-joint, partial resection of ankle, excision of tumour over the parotid gland, besides many eye operations.

The operations on the eye, for which an anæsthetic is required, demand, with few exceptions, narcotism as profound as can be safely produced. The reflex movements, produced by contact of instruments with the cornea, must cease before the operation begins; and, as a rule, they do not cease until a stage of narcotism, beyond that of insensibility to pain, is reached. I do not now inquire how far this need of profound narcotism explains the fact of a great chloroform mortality in ophthalmic practice. In regard to this point, it should be borne in mind that the number of cases in an eye-hospital requiring an anæsthetic is immensely greater than in a general hospital of equal size, and that a large apparent mortality in the former thus becomes a small death-rate. 
At Moorfields, from eight to twelve patients are anæsthetised during the few hours of each day devoted to operations: thus the time consumed by each administration is of some, although secondary, importance. A slow anæsthetic is hardly admissible. Ether has been used there since August in a large number of cases. No difficulty has been found in speedily producing perfect muscular quiescence. The time necessary for complete narcotism is about the same as with chloroform-certainly not longer.

A marked and invariable feature has been the absence of all disposition to syncope. There have been no sudden failures of pulse, with pallid lips, even under the most lavish use of the anresthetic; on the contrary, complete muscular relaxation was generally associated with a flushed face and full pulse. A folded towel enclosing a piece of sponge has been the only inhaler used. Only when this is soaked with anhy. drous ether is a vapour of adequate concentration obtained. The presence of even small percentages of water reduces the volatility of ether very considerably, and prevents a satisfactory result.

Without disparagement to less simple devices for administering a vapour of known strength, it may be asserted that the folded towel possesses great practical convenience, and has yet to be proved dangerous. By no other method can a vapour of adequate concentration be so readily obtained. Not only is there no danger in this lavish use of the anæsthetic, but narcotism is produced more quickiy, and with less cerebral excitement, than is apt to result from too weak a dose at the outset. If the latter fault be committeci, the patient becomes noisy and violent, and the vessels of his face and head become turgid-a condition unfavourable to many operations. On the other hand, by an adequate dose, narcotism, without excitement, is produced, and can then be easily maintained for an indefinite period by a less concentrated vapour.

The sole objection to this mode of administration is the overpowering scnse of impending suffocation, apt to be produced by the first contact of the vapour with the air-passages. While my experience-accords with that of Dr. Joy Jeffries as to the necessity for a strong dose at the outset, I do not believe with him that a forcible administration, in spite of the patient's struggles, is a desirable or necessary practice. By a little management in the case of adults, it may generally be dispensed with. They often take it without struggling, when forewarned that a few deep inhalations resolutely taken dispel the sense of choking. When their voluntary efforts fail to overcome the spasm of glottis provoked by the vapour, it is best to relieve them by momentarily raising the towel from the face, and allowing one full inspiration of unmixed air before panic takes possession of them. By this mancurre the spasm instantly disappears, and does not return when a concentrated vapour is again inhaled. It should be remembered that the struggling occurs before the ether has had time to affect the brain, and the cause of itthe irritation of the air-passages-disappears at the very commencement of anesthesia, after one or two full inhalations of vapour. Occasionally, no doubt, an adult is entirely wanting in self-command, and fails to co-operate in the administration. A little force may then be needed, but should not be prolonged more than a few seconds. After a few inhalations of strong vapour, a breath or two of unmixed air should be given, and the inhalation then resumed, probably without resistance from the patient.

Children must be narcotised forcibly, but their struggles are neither so violent nor so distressing to bystanders as those of adults. Ether does not blister even after prolonged contact with the skin, and in this respect is altogether different from chloroform and methylene.

The recovery from a properly conducted etherisation is usually characterised by a quiet, rather profound, slumber. Even patients known to be intemperate alcohol-drinkers do not recover more noisily than from chloroform.

After severe operations under chloroform, most surgeons have had to lament instances of death from obstinate chloroform vomiting, in which the shock of the operation is prolonged and intensified by incessant nausea, and the stomach continues, day after day, to reject food, until the patient dies exhausted. Mr. Curling records an instance after lumbar colotomy. A similar case occurred in my hands : they are by no means very rare. Operations implicating the pelvic and abdominal viscera appear to be especially liable to this accident; and it would not be inopportune were obstetricians now to give the result of their experience on this point, in cases demanding deeper and more prolonged chloroform narcotism than is usual in normal labour.

More than a few months' experience is of course required to determine whether ether ever exerts this formidable effect on the stomach. Thus far, no such instance of it has occurred in my hands, or has come to my knowledge. In a recent case of ovariotomy, my housesurgeon, Mr. Sargant, maintained etherisation for nearly three-quarters of an hour without inducing retching. The intestines never even came into view during the operation: there was no subsequent vomiting. In a tedious operation of lumbar colotomy performed by me last month, the narcotism lasted more than half-an-hour. The patient vomited once immediately on leaving the theatre, but had no subsequent nausea. On the following day he was able to retain liquid food in his stomach, and has since made a good recovery from the operation.

Thus far my impression is, that ether is less dangerous to life than chloroform, on account of its inaptitude to produce cardiac syncope ; that its administration is rarely if ever followed by obstinate and dangerous nausea ; that it narcotises as quickly and as certainly as chloroform, and with as complete muscular quiescence; and that recovery from it is generally quiet and satisfactory.

\section{THE MORBID EFFECTS OF ALCOHOL.}

By W. H. DICKINSON, M.D.Cantab., F.R.C.P., Senior Assistant-Physician and Lecturer on Pathology, St. George's Hospital Physician to the Hospital for Sick Children; Corresponding Member of the Academy of Medicine, New York; etc.

As the leader in last week's JOURNAL, upon the morbid effects of alco. hol, is pointedly directed against myself, I claim the right of reply. The writer, who apparently did not hear the paper, has commented in a manner which, even on the showing of the abstract, appears to me to be unjustifiable. He has misrepresented the purport of the argument and disregarded the stated limits of the inquiry. In comparing traders in liquor with persons otherwise employed and not ostensibly drunken, I was careful to state that the infere nce that those who got liquor in the way of business for nothing took more of it than those who had to buy it, related to the general average. Among the I49 traders in drink may have been a teetotaller; some of the contrasted class may have been intemperate in spite of the care used to exclude such. But it can scarcely be doubted that the arerage of imbibition was greater on the side of gratuitous drink, and sufficiently greater tc. give preponderance in the class where it was current to the diseases which drink engenders. The writer of the article admits the notorious inebriety of traders in liquor, but "demurs to the assumption that the morbid appearances found in the dead bodies of all hospital patients who have not been engaged in the liquor-traffic are certainly not the result of alcoholism"; and describes as fallacious "the assumption that, excepting known drunkards, temperance may be taken for granted among the entire population." He is welcome to demur to such fallacies; they do not belong to me. As to persons not dealing with liquor or ostensibly drunken, my assumption is not that their diseases are invariably unconnected with drink, but that they are less often connected with drink than are the diseases of those who do so trade and are thus admittedly inebriate. The question is not between drink and. no drink, or even between drunkenness and no drunkenness, but between more and less. All $I$ assume is, that an average poor man who drinks at others' cost will take more than another who drinks at his own. If the writer question this, and deny that there is more intemperance on one side than the other, let me ask why it is that with. the drink-traders cirrhosis of the liver is more than twice as frequent as with the contrasted class. If there be no excess of drink on one side, the fundamental proposition of my paper falls to the ground. If the excess exist where I have placed it, and be such as to tell upon health, then not my conclusions, but his criticisms, must be described as " mis. leading and mischievous."

The article then proceeds to inform us that "an ordinary post mortcm record as to the appearance of the kidney affords no indication of the actual amount of disease. A kidney, which on a superficial examination might pass for healthy, may reveal to a skilled microscopic observer extensive and advanced degeneration." Are we to infer from this that it is of no use looking at the kidney except through a micro. scope? Bright made a few useful observations with the naked eye, an instrument, indeed, which is by no means without value in the detection of "extensive and advanced" renal changes. It needs no microscope to determine whether the kidney be twice or half its proper weight, or whether the surface be granular or the section that of a parsnip. The unassisted but practised eye, which though it does not scrutinise disjointed bricks comprehends the building, is a surer test for potential renal disease than the fragmentary microscopic examination which only is habitually practicable. And because we have not evidence of both kinds, shall we reject the more important?

The writer is kind enough to suggest total abstainers as a standard of comparison-an idea sufficiently obvious to have occurred to myself. The number is to be five hundred. Will he place me under still further obligation by producing them? a process which he himself admits 